\title{
Reply to the Letter to the Editor: Predictive Values of C-Reactive Protein and Neutrophil to Lymphocyte Ratio in Detecting Anastomotic Leak in Open Colorectal Surgery
}

\author{
Michal Mik \\ Department of General and Colorectal Surgery, Medical University of Lodz, Lodz, Poland
}

Dear Editor,

As a reply to the Letter to Editor written by Paliogiannis and Zinellu [1], first I would like to thank you for these questions. During last few years in our department, we have been estimating predictive values and the level of accuracy of some diagnostic tests in intra-abdominal septic complications in colorectal cancer surgery. The estimation of the negative predictive value (NPV) and positive predictive value (PPV) of these tests is dependent on the prevalence of the disease (i.e., anastomotic leak $[\mathrm{AL}]$ ), as it was mentioned by my colleagues. In our study that was published in Digestive Surgery, we assumed the prevalence of AL at a substantially higher level than $4.6 \%$. Retrospectively, we based the prevalence of the occur- rence of $\mathrm{AL}$ among patients operated on during longer period than in this prospective trial, precisely between 2003 and 2014 in all patients operated on our institution. The group included 1,534 patients, and in our appraisal, the sample size seemed to be more representative for the occurrence of $\mathrm{AL}$ in this population. In the methods section, not all the statistical details were provided and we believe it could have caused some obscurities. I hope that the addendum helped in clarifying some particularities. The PPV and NPV were calculated using the standard statistical methods from a contingency table by assuming our large population and deriving the PPV and NPV for that population, using the prevalence, sensitivity, and specificity proportions to populate the table with values for true- and false-positive, and trueand false-negative test results [2]. Regarding the higher prevalence of AL, the PPV and NPV reached the values revealed in our study.

\section{References}

1 Paliogiannis P, Zinellu A: Predictive values of C-reactive protein and neutrophil to lymphocyte ratio in detecting anastomotic leak in open colorectal surgery. Dig Surg 2017, DOI: 10.1159/000481415.

2 Bland M: An Introduction to Medical Statistics, ed 3. Oxford, Oxford University Press, 2000.

\section{KARGER}

(c) 2017 S. Karger AG, Basel

E-Mail karger@karger.com

www.karger.com/dsu
Michal Mik

Department of General and Colorectal Surgery

Medical University of Lodz

Plac Hallera 1, PL-90-647 Lodz (Poland)

E-Mail m.mik@wp.pl 